\title{
Sonographic optic nerve sheath diameter as a surrogate measure for intracranial pressure in anesthetized patients in the Trendelenburg position
}

\author{
Ji-Hyun Chin ${ }^{1}$, Hyungseok Seo ${ }^{1}$, Eun-Ho Lee', Joohyun Lee ${ }^{1}$, Jun Hyuk Hong ${ }^{2}$, Jai-Hyun Hwang ${ }^{1}$ \\ and Young-Kug Kim ${ }^{1 *}$
}

\begin{abstract}
Background: It remains to be elucidated whether the Trendelenburg position increases intracranial pressure (ICP). ICP can be evaluated by measuring the sonographic optic nerve sheath diameter (ONSD). We investigated the effect of the isolated Trendelenburg position on ONSD in patients undergoing robot-assisted laparoscopic radical prostatectomy. Additionally, we evaluated the effect of the Trendelenburg position combined with pneumoperitoneum on ONSD.

Methods: Twenty-one patients scheduled for robot-assisted laparoscopic radical prostatectomy were enrolled. Sonographic ONSDs and hemodynamic parameters were measured at specific time points: in the supine position after induction of anesthesia, $3 \mathrm{~min}$ after the steep Trendelenburg position ( $35^{\circ}$ incline), $3 \mathrm{~min}$ after the steep Trendelenburg position combined with pneumoperitoneum, and in the supine position after desufflation of the pneumoperitoneum.

Results: The ONSD 3 min after the steep Trendelenburg position was significantly higher than that of the supine position after induction of anesthesia $(5.1 \pm 0.3 \mathrm{~mm}$ vs. $4.5 \pm 0.4 \mathrm{~mm})$. In addition, the ONSD $3 \mathrm{~min}$ after the steep Trendelenburg position combined with pneumoperitoneum was higher than that of the supine position after induction of anesthesia $(4.9 \pm 0.4 \mathrm{~mm}$ vs. $4.5 \pm 0.4 \mathrm{~mm})$. The ONSD in the supine position after desufflation of the pneumoperitoneum was similar to that in the supine position after induction of anesthesia.

Conclusions: Use of the isolated steep Trendelenburg position, for even a short duration, increased the sonographic ONSD, providing a better understanding of the effect of only a transient steep Trendelenburg position on ONSD as a surrogate measure for ICP.
\end{abstract}

Keywords: Intracranial pressure, Optic nerve sheath diameter, Trendelenburg position

\section{Background}

The Trendelenburg position has long been believed to increase intracranial pressure (ICP), an idea that may be derived from previous reports $[1,2]$. In these studies, the ICP increased when prolonged comatose patients with severe brain injury and neurosurgical patients were placed in the head-down position [1,2]. However, the Trendelenburg position differs from the head-down

\footnotetext{
* Correspondence: kyk@amc.seoul.kr

'Department of Anesthesiology and Pain Medicine, Asan Medical Center, University of Ulsan College of Medicine, 88 Olympic-ro 43-gil, Songpa-gu, Seoul 138-736, Republic of Korea

Full list of author information is available at the end of the article
}

position used in those studies, in that the head is straight along the axis of the body in the Trendelenburg position, whereas the head is extended back and the body remains straight in the head-down position. In addition, the combined effect of a prolonged Trendelenburg position and pneumoperitoneum has been reported to increase ICP [3]. It is notable that the specific effect of the isolated Trendelenburg position on ICP has not been fully evaluated, given the frequent use of the Trendelenburg position in non-neurologic patients in daily practice. The invasiveness of the conventional method for measuring ICP might not allow the ICP of non-neurologic patients to be evaluated. 
It has recently been determined that the ICP can be evaluated by noninvasive ocular sonography [4-7]. The retrobulbar segment of the optic nerve is surrounded by a distensible subarachnoid space, which can inflate when cerebrospinal fluid pressure increases [8,9]. An increased optic nerve sheath diameter (ONSD) detected by ocular sonography is associated with clinical signs of high ICP in adults with traumatic brain injury and in children with hydrocephalus or liver failure [9-13]. Moreover, the ONSD has been correlated with ICP invasively measured by an intraparenchymal catheter inserted into the frontal lobe in sedated patients receiving neurocritical care, including patients with severe traumatic brain injury [14]. Rapid and safe sonographic measurement of ONSD may enable patients to be screened for increased ICP.

We, therefore, aimed to investigate the effect of the isolated Trendelenburg position on ONSD to examine possible changes in ICP in patients undergoing robotassisted laparoscopic radical prostatectomy. Additionally, we evaluated the effect of the Trendelenburg position combined with pneumoperitoneum on ONSD in these patients.

\section{Methods}

\section{Patients}

The study protocol was approved by the Institutional Review Board at Asan Medical Center (AMC IRB 20130408) and written informed consent was obtained from each patient scheduled for robot-assisted laparoscopic radical prostatectomy. This study was registered with the Clinical Research Information Service (KCT0000746). Patients with pre-existing neurological or cerebrovascular disease were excluded.

After routine hemodynamic monitoring (electrocardiogram, noninvasive blood pressure, and pulse oximetry) was applied and sensors for an INVOS 5100 cerebral/ somatic oximeter (Coviden Inc., Dublin, Ireland) were attached to the right and left frontal areas, anesthesia was induced using a bolus intravenous injection of 5 $\mathrm{mg} / \mathrm{kg}$ thiopental sodium followed by $0.1 \mathrm{mg} / \mathrm{kg}$ vecuronium. After tracheal intubation, patients were mechanically ventilated with a tidal volume of $8 \mathrm{ml} / \mathrm{kg}$ of ideal body weight at a respiratory rate of $10-16$ breaths/min to maintain end-tidal $\mathrm{CO}_{2}$ partial pressure $\left(\mathrm{ETCO}_{2}\right)$ between 30 and $35 \mathrm{mmHg}$. Positive end-expiratory pressure was not applied and the inspiratory-to-expiratory time ratio was set at 1:2. Anesthesia was maintained with $2-3 \mathrm{vol} \%$ sevoflurane plus a continuous infusion of $2-5 \mathrm{ng} / \mathrm{ml} \mathrm{remi-}$ fentanil with $50 \%$ oxygen using medical air.

\section{Ocular sonography}

The ONSD was measured sonographically by investigators trained in ocular sonography, as described previously $[15,16]$. Briefly, patients were placed in the supine position with their eyes closed, and a thick gel layer was applied to the closed upper eyelid. A 7.5- $\mathrm{MHz}$ linear probe was placed on the gel without excessive pressure and adjusted to the proper angle to display the optimal contrast between the retrobulbar echogenic fat tissue and the vertical hypoechoic band. An ultrasound beam was focused on the retrobulbar area using the lowest possible acoustic power that could measure the ONSD. The ONSD was measured at $3 \mathrm{~mm}$ behind the optic disc. Measurements were performed in the transverse and sagittal planes of both eyes, and the mean values of four measurements at each time point were used for analysis. To determine intra-observer and inter-observer variability, a random sample of $25 \%$ of ONSD measurements was submitted twice to the first investigator and once to a second investigator. The inter-observer variability was then calculated as the mean absolute difference between the two readings from the first and second investigators divided by their mean and expressed as a percentage. Similarly, the intra-observer variability was calculated as the mean absolute difference between the two readings from the first investigator divided by their mean and expressed as a percentage.

\section{Study protocol}

When hemodynamically stable conditions were reached, four measurements were taken, as follows: in the supine position after induction of anesthesia $\left(\mathrm{T}_{\mathrm{SUP}}\right), 3 \mathrm{~min}$ after the steep Trendelenburg position $\left(35^{\circ}\right.$ incline) $\left(\mathrm{T}_{\text {TREN }}\right), 3$ min after the steep Trendelenburg position combined with pneumoperitoneum $(15 \mathrm{mmHg}$ of insufflation pressure) $\left(\mathrm{T}_{\mathrm{T}+\mathrm{P}}\right)$, and in the supine position after desufflation of the pneumoperitoneum $\left(\mathrm{T}_{\mathrm{END}}\right)$. After $\mathrm{T}_{\mathrm{TREN}}$, the position was changed to the supine position for $10 \mathrm{~min}$, which was followed by $\mathrm{T}_{\mathrm{T}+\mathrm{P}}$. Parameters measured at each time point included the ONSD, systolic blood pressure (SBP), diastolic blood pressure (DBP), mean blood pressure (MBP), heart rate (HR), tympanic body temperature (BT), airway peak pressure $\left(\mathrm{P}_{\text {peak }}\right)$, airway plateau pressure $\left(\mathrm{P}_{\text {plat }}\right)$, $\mathrm{ETCO}_{2}$, and regional cerebral oxygen saturation $\left(\mathrm{rSO}_{2}\right)$ using near-infrared spectroscopy. In addition, arterial $\mathrm{CO}_{2}$ partial pressure $\left(\mathrm{PaCO}_{2}\right)$, and hemoglobin concentration were measured at $\mathrm{T}_{\mathrm{SUP}}$ and $\mathrm{T}_{\mathrm{END}}$.

\section{Statistical analysis}

Continuous variables are expressed as mean \pm SD or median (interquartile range). Categorical variables are expressed as number (percentage). A power analysis based on our pilot study data suggested that a minimum sample size of 17 patients would be required to detect a mean 0.5 $\mathrm{mm}$ difference (SD: $0.58 \mathrm{~mm}$ ) in the ONSD between $\mathrm{T}_{\text {SUP }}$ and $\mathrm{T}_{\text {TREN }}$ with a power of $90 \%$ at a significance of $P<$ 0.05 . Expecting a dropout rate of about $20 \%$, we aimed to enroll 21 patients. One-way repeated measures analysis of 
variance (ANOVA) was used to evaluate the effect of several different positions under general anesthesia on the change in the ONSD, SBP, DBP, MBP, HR, $\mathrm{P}_{\text {peak }}$, $\mathrm{P}_{\text {plat }}$, and $\mathrm{rSO}_{2}$. If any interaction was significant, post hoc analysis was performed using the Holm-Sidak method. Oneway repeated measures ANOVA on rank was used to evaluate the effect of the different positions under general anesthesia on the change in the BT and $\mathrm{ETCO}_{2}$. If any interaction was significant, post hoc analysis was performed using Tukey's test. A paired $t$ test was performed to evaluate $\mathrm{PaCO}_{2}$ and hemoglobin concentrations measured at $\mathrm{T}_{\mathrm{SUP}}$ and $\mathrm{T}_{\mathrm{END}}$. A $P$ value $<0.05$ was considered statistically significant. All statistical analyses were performed using SigmaPlot software, version 12.3 (Systat Software Inc., San Jose, CA).

\section{Results}

Twenty-one patients scheduled for robot-assisted laparoscopic radical prostatectomy were enrolled and evaluated. All 21 enrolled patients completed the study protocol. The patients' characteristics are shown in Table 1. Of the 21 patients, 12 had preoperative hypertension. There was no significant difference in MBP between patients with and without hypertension. There was no patient with chronic obstructive pulmonary disease.

The ONSDs at several positions were significantly different from that of the supine position during surgery $(P<0.001)$ (Table 2$)$. The ONSD at $\mathrm{T}_{\text {TREN }}$ significantly increased compared with that at $\mathrm{T}_{\text {SUP }}(5.1 \pm 0.3 \mathrm{~mm} v s$. $4.5 \pm 0.4 \mathrm{~mm}$; Figure 1). When patients with or without preoperative hypertension were separately considered, similar results were shown (with: $4.5 \pm 0.5 \mathrm{~mm}$ at $\mathrm{T}_{\mathrm{SUP}}$ vs. $5.1 \pm 0.3 \mathrm{~mm}$ at $\mathrm{T}_{\mathrm{TREN}}, P<0.001$; without: $4.5 \pm 0.4$ $\mathrm{mm}$ at $\mathrm{T}_{\text {SUP }} v s .5 .0 \pm 0.3 \mathrm{~mm}$ at $\mathrm{T}_{\mathrm{TREN}}, P=0.003$ ).

In addition, the ONSD at $\mathrm{T}_{\mathrm{T}+\mathrm{P}}$ increased compared with that at $\mathrm{T}_{\text {SUP. }}$. At $\mathrm{T}_{\mathrm{END}}$, the ONSD was similar to that at $\mathrm{T}_{\mathrm{SUP}}$. The intra- and inter-observer variabilities of the ONSD measurement were $1.8 \%$ and $2.8 \%$, respectively. Intraoperative variables, including hemodynamic

\section{Table 1 Demographic and perioperative data}

\begin{tabular}{ll}
\hline Age (years) & $63.6 \pm 7.5$ \\
Height $(\mathrm{cm})$ & $167.1 \pm 5.9$ \\
Weight $(\mathrm{kg})$ & $66.9 \pm 7.3$ \\
Hypertension & $12(57.1 \%)$ \\
Diabetes mellitus & $3(14.3 \%)$ \\
Hemoglobin (g/dl) & \\
$\quad$ Immediately after induction & $13.4 \pm 0.9$ \\
$\quad$ At the end of surgery & $11.9 \pm 1.1$ \\
Operation time (min) & $172.9 \pm 33.3$ \\
Anesthetic time (min) & $227.5 \pm 38.9$ \\
\hline
\end{tabular}

Values are mean \pm SD or number (percentage). and respiratory variables, at each time point are shown in Table 2. The $\mathrm{rSO}_{2}$ did not show significant changes across all time points.

\section{Discussion}

We found in our present study that the ONSD, as measured by ocular sonography, increased $3 \mathrm{~min}$ after the isolated steep Trendelenburg position in mechanically ventilated patients. In addition, we observed that the ONSD increased after the patient was placed in the steep Trendelenburg position combined with pneumoperitoneum.

The ONSD measured by ocular sonography has been found to correlate with ICP, suggesting that it could be used as a surrogate for ICP. Various cut-off values have been used to distinguish high from normal ICP [6,7,13-15]. Several previous studies reported that the ONSD cut-off value of $5 \mathrm{~mm}$ was sensitive and specific for the identification of computed tomographic findings suggestive of increased ICP [6,13]. Importantly, the ONSD cut-off value of $5 \mathrm{~mm}$ was found to be able to distinguish an ICP $>20 \mathrm{mmHg}$ measured by ventriculostomy, showing an area under a receiver operator characteristics curve of 0.93 with a sensitivity of $88 \%$ and specificity of $93 \%$ in patients with clinical or radiologic signs of increased ICP [14]. On the other hand, a previous study used several lower cut-off values, from $4.7 \mathrm{~mm}$ to $4.9 \mathrm{~mm}$, as well as $5.0 \mathrm{~mm}$, to investigate the accuracy of each cut-off in detecting high ICP in patients with fluctuating and stable ICP [17].

Physicians often establish the Trendelenburg position in both surgical and non-surgical conditions, such as when implementing central venous catheterization to facilitate venous access, performing surgical procedures on the lower abdominal or pelvic organs to obtain a good surgical field, and treating hypotensive patients to improve hemodynamics, despite a lack of evidence for its effects. However, the position has been considered to increase ICP, which has a normal range of 7-15 mmHg in supine healthy adults [18]. This increase was seen in previous studies that found that the head-down position increased ICP in neurologic patients [1]. However, the head-down position, which is frequently performed during neurologic surgery, is different from the Trendelenburg position. The head-down position extends the head and neck from the normal supine position, whereas the Trendelenburg position inclines the whole body in a supine position. In addition, few reports have included non-neurologic patients when evaluating the effect of the isolated Trendelenburg position on ICP. Therefore, we believe that our study design for assessing the effects of the position on ONSD as a surrogate measure for ICP is unique.

We found from our current analysis that the ONSD increased to approximately $5.0 \mathrm{~mm}$ immediately after 
Table 2 Intraoperative variables

\begin{tabular}{|c|c|c|c|c|}
\hline & $\mathrm{T}_{\text {SUP }}$ & $\mathrm{T}_{\text {TREN }}$ & $\mathrm{T}_{\mathrm{T}+\mathrm{P}}$ & $T_{\text {END }}$ \\
\hline$\overline{\mathrm{ONSD}}(\mathrm{mm})$ & $4.5 \pm 0.4$ & $5.1 \pm 0.3^{*}$ & $4.9 \pm 0.4^{*}$ & $4.4 \pm 0.4$ \\
\hline $\mathrm{SBP}(\mathrm{mmHg})$ & $106.9 \pm 20.2$ & $99.6 \pm 14.2$ & $132.7 \pm 19.8^{*}$ & $112.5 \pm 16.6$ \\
\hline $\mathrm{DBP}(\mathrm{mmHg})$ & $56.8 \pm 10.5$ & $56.0 \pm 7.0$ & $76.7 \pm 10.8^{*}$ & $61.7 \pm 13.0$ \\
\hline $\mathrm{MBP}(\mathrm{mmHg})$ & $73.5 \pm 13.1$ & $70.5 \pm 8.9$ & $95.3 \pm 11.7^{*}$ & $78.6 \pm 13.8$ \\
\hline HR (beats/min) & $66.4 \pm 9.6$ & $59.2 \pm 8.5$ & $60.2 \pm 7.5$ & $65.3 \pm 9.1$ \\
\hline $\mathrm{BT}\left({ }^{\circ} \mathrm{C}\right)$ & $36.5(36.3-36.8)$ & $36.3(36.0-36.7)$ & $36.1(35.8-36.3)^{*}$ & $35.9(35.5-36.5)^{*}$ \\
\hline$P_{\text {peak }}\left(\mathrm{cmH}_{2} \mathrm{O}\right)$ & $12.1 \pm 2.2$ & $18.1 \pm 3.1^{*}$ & $26.8 \pm 4.0^{*}$ & $15.5 \pm 2.4^{*}$ \\
\hline$P_{\text {plat }}\left(\mathrm{cmH}_{2} \mathrm{O}\right)$ & $11.5 \pm 2.1$ & $17.5 \pm 3.1^{*}$ & $25.9 \pm 4.0^{*}$ & $14.3 \pm 2.5$ \\
\hline $\mathrm{ETCO}_{2}(\mathrm{mmHg})$ & $32.0(31.0-33.0)$ & $30.0(29.5-32.0)^{*}$ & $33.0(32.0-34.0)$ & $35.0(32.5-36.5)^{*}$ \\
\hline $\mathrm{PaCO}_{2}(\mathrm{mmHg})$ & $40.3 \pm 3.0$ & NA & NA & $47.1 \pm 4.0^{*}$ \\
\hline $\mathrm{rSO}_{2}(\%)$ & $73.6 \pm 5.5$ & $70.3 \pm 4.6$ & $70.9 \pm 5.3$ & $72.8 \pm 3.8$ \\
\hline
\end{tabular}

Values are mean \pm SD or median (interquartile range). ONSD: optic nerve sheath diameter; SBP: systolic blood pressure; DBP: diastolic blood pressure; MBP: mean blood pressure; $\mathrm{HR}$ : heart rate; $\mathrm{BT}$ : tympanic body temperature; $\mathrm{P}_{\text {peak: }}$ airway peak pressure; $\mathrm{P}_{\text {plat: }}$ airway plateau pressure; $\mathrm{ETCO}_{2}$ : end-tidal $\mathrm{CO}_{2}$ partial pressure; $\mathrm{PaCO}_{2}$ : arterial $\mathrm{CO}_{2}$ partial pressure; $\mathrm{rSO}_{2}$ : regional cerebral oxygen saturation by near-infrared spectroscopy; NA: not available; $\mathrm{T}_{\mathrm{Sup}}$ : in the supine position after induction of anesthesia; $\mathrm{T}_{\text {TREN }}: 3 \mathrm{~min}$ after the steep Trendelenburg position ( $35^{\circ}$ incline); $\mathrm{T}_{\mathrm{T}+\mathrm{P}}: 3 \mathrm{~min}$ after the steep Trendelenburg position combined with pneumoperitoneum; $\mathrm{T}_{\mathrm{END}}$ : in the supine position after desufflation of the pneumoperitoneum. ${ }^{*} \mathrm{P}<0.05$ compared with $\mathrm{T}_{\text {SUP. }}$

patients were placed in the isolated steep Trendelenburg position, reflecting a high ICP, defined as $20 \mathrm{mmHg}$ [14]. The Trendelenburg position may disturb cerebral venous drainage by increasing the impedance of the lungs to inflation [19]. Therefore, when the lungs are ventilated with the same tidal volume used for the supine position, the Trendelenburg position may lead to higher intrathoracic pressure and subsequently increase the ICP by the transmission of intrathoracic pressure to the intracranial space [20]. Indeed, our current results indicated increased airway pressure during the Trendelenburg position. It has been reported that the ONSD increased after desufflating pneumoperitoneum and before resuming a neutral level at

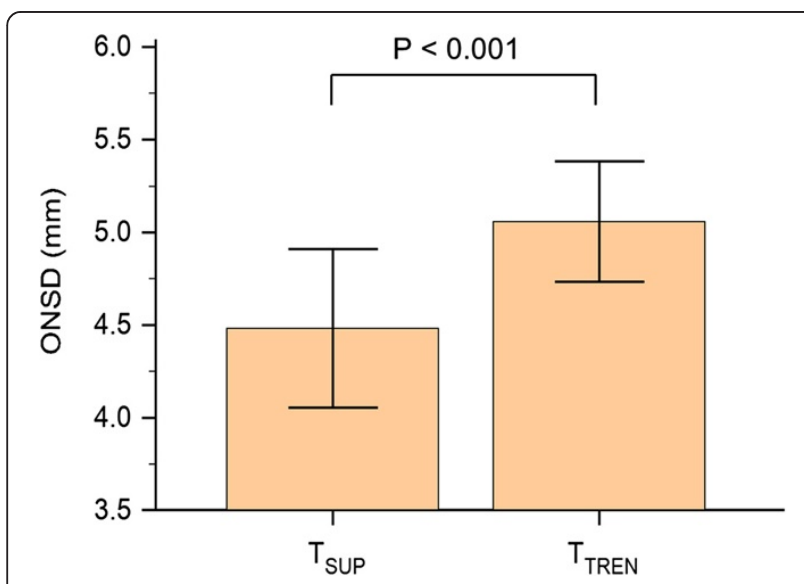

Figure 1 Change in optic nerve sheath diameter (ONSD) between the supine and the steep Trendelenburg position. A significant increase was found in the ONSD 3 min after the patient position was changed from supine to steep Trendelenburg. Tsup: in the supine position after induction of anesthesia; TREEN 3 min after the steep Trendelenburg position ( $35^{\circ}$ incline). the end of surgery [21]. This previous finding might support our results. However, the $\mathrm{PaCO}_{2}$ is expected to increase at the end of surgery, although this increase was not shown in the previous study, and this increased $\mathrm{PaCO}_{2}$ might affect the ONSD. Therefore, the effect of the isolated Trendelenburg position on ONSD may not have been exclusively evaluated in the previous study.

In contrast to our current results, it has been reported that the ONSD measured $10 \mathrm{~min}$ after pneumoperitoneum combined with the Trendelenburg position did not increase under general anesthesia with sevoflurane [22]. Increased cerebral blood flow might be compensated for by cerebrospinal fluid translocation to the vascular component during the 10 min interval between the position change and the measurement of the ONSD. However, our present study measured the ONSD $3 \mathrm{~min}$ after pneumoperitoneum combined with the Trendelenburg position. This duration might be too short for the patient to develop compensation mechanisms. Interestingly, another study assessed the ONSD during laparoscopic prostatectomy, and found an increased ONSD 10 min after pneumoperitoneum combined with the Trendelenburg position [3]. This previous study used desflurane, which induced a greater increase in cerebral blood flow than sevoflurane [23], for anesthetic maintenance. Differences in the anesthetic drug might contribute, at least in part, to the conflicting results.

The effect of $\mathrm{ETCO}_{2}$ on ICP did not accentuate the increase in the ONSD observed in the steep Trendelenburg position because the $\mathrm{ETCO}_{2}$ level decreased during study period. Our present result suggests the importance of careful control of $\mathrm{ETCO}_{2}$ in anesthetized patients in the Trendelenburg position. However, the previous report might be confusing for clinicians when adjusting the 
$\mathrm{ETCO}_{2}$ during robot-assisted laparoscopic radical prostatectomy, because it showed an unexplained small difference between the $\mathrm{ETCO}_{2}$ and the $\mathrm{PaCO}_{2}$ over the whole period when the Trendelenburg position combined with pneumoperitoneum was adopted [3], unlike the results of our present analyses and previous studies [24-26].

We found that the $\mathrm{rSO}_{2}$ was unchanged at all of the predetermined time points under general anesthesia. The $\mathrm{rSO}_{2}$, which reflects a regional balance between cerebral oxygen supply and demand, has been studied to identify the effects of various positions on cerebral blood flow under diverse positions during laparoscopic surgery, yielding conflicting results [27-30]. The inconsistencies among studies may be partly due to the characteristics of near-infrared spectroscopy, which mainly reflects the venous compartment (artery:vein $=25 \%: 75 \%$ ), and its lack of accuracy for reflecting cerebral blood flow compared with jugular bulb oxygen saturation [31].

Our study has the following limitations. First, we studied a fixed degree of incline when establishing the Trendelenburg position. Further analysis of whether there is a graded association between the degree of incline during the Trendelenburg position and the change in the ONSD is needed. Second, our investigations were conducted under general anesthesia without excluding the effect of anesthetics on ONSD. Therefore, the change in the ONSD when the position was changed under general anesthesia can differ from that in awake patients, who were previously found not to show significant changes in the ONSD when placed in the Trendelenburg position [32]. An attenuated ability to maintain homeostasis in cerebral blood flow during general anesthesia using volatile anesthetics would be a plausible explanation, because volatile anesthetics have a dose-dependent cerebral vasodilatory effect [33]. Third, there are no general consensus over optimal cut-off values of ONSD, despite of use of ONSD cut-off value of $5 \mathrm{~mm}$ to detect increased ICP $>20 \mathrm{mmHg}$ in the present study [6,7,13-15]. Furthermore, the accuracy of ONSD in detecting elevated ICP remains controversial $[7,17,34]$. Therefore, the present study does not definitively prove that there is an elevated ICP with steep Trendelenburg positioning, but does indicate that there is a likely rise in ICP which may reach critical levels in some patients.

\section{Conclusions}

The sonographic ONSD as a surrogate measure for ICP increases when patients are placed in the isolated steep Trendelenburg position even for a short duration. Monitoring of the sonographic ONSD may provide useful information on changes in ICP when the steep Trendelenburg position is inevitably performed.

\section{Abbreviations}

ICP: Intracranial pressure; ONSD: Optic nerve sheath diameter; $\mathrm{ETCO}_{2}$ : End-tidal $\mathrm{CO}_{2}$ partial pressure; $\mathrm{rSO}_{2}$ : Regional cerebral oxygen saturation; $\mathrm{PaCO}_{2}$ : Arterial $\mathrm{CO}_{2}$ partial pressure; ANOVA: Analysis of variance.

\section{Competing interests}

The authors declare that they have no competing interests.

\section{Authors' contributions}

JHC: conception and design of study, acquisition of data, analysis and interpretation of data, drafting the manuscript. HS: acquisition of data, analysis and interpretation of data. EHL: conception and design of study, analysis and interpretation of data. JL: acquisition of data, analysis and interpretation of data. JHH: conception and design of study, critical revision of the manuscript. JHH: conception and design of study, supervision of the study. YKK: conception and design of study, analysis and interpretation of data, critical revision of the manuscript, supervision of the study. All authors read and approved the final manuscript.

\section{Author details}

'Department of Anesthesiology and Pain Medicine, Asan Medical Center, University of Ulsan College of Medicine, 88 Olympic-ro 43-gil, Songpa-gu, Seoul 138-736, Republic of Korea. ${ }^{2}$ Department of Urology, Asan Medical Center, University of Ulsan College of Medicine, Seoul, South Korea.

Received: 19 November 2014 Accepted: 19 March 2015

Published online: 31 March 2015

\section{References}

1. Lee ST. Intracranial pressure changes during positioning of patients with severe head injury. Heart Lung. 1989;18(4):411-4.

2. Mavrocordatos P, Bissonnette B, Ravussin P. Effects of neck position and head elevation on intracranial pressure in anaesthetized neurosurgical patients: preliminary results. J Neurosurg Anesthesiol. 2000;12(1):10-4.

3. Kim MS, Bai SJ, Lee JR, Choi YD, Kim YJ, Choi SH. Increase in intracranial pressure during carbon dioxide pneumoperitoneum with steep trendelenburg positioning proven by ultrasonographic measurement of optic nerve sheath diameter. J Endourol. 2014;28(7):801-6.

4. Geeraerts T, Merceron S, Benhamou D, Vigue B, Duranteau J. Non-invasive assessment of intracranial pressure using ocular sonography in neurocritical care patients. Intensive Care Med. 2008;34(11):2062-7.

5. Geeraerts T, Launey Y, Martin L, Pottecher J, Vigue B, Duranteau J, et al. Ultrasonography of the optic nerve sheath may be useful for detecting raised intracranial pressure after severe brain injury. Intensive Care Med. 2007;33(10):1704-11.

6. Major R, Girling S, Boyle A. Ultrasound measurement of optic nerve sheath diameter in patients with a clinical suspicion of raised intracranial pressure. Emerg Med J. 2011;28(8):679-81.

7. Kristiansson H, Nissborg E, Bartek Jr J, Andresen M, Reinstrup P, Romner B. Measuring elevated intracranial pressure through noninvasive methods: a review of the literature. J Neurosurg Anesthesiol. 2013;25(4):372-85.

8. Liu D, Kahn M. Measurement and relationship of subarachnoid pressure of the optic nerve to intracranial pressures in fresh cadavers. Am J Ophthalmol. 1993;116(5):548-56.

9. Hansen $\mathrm{HC}$, Helmke K. Validation of the optic nerve sheath response to changing cerebrospinal fluid pressure: ultrasound findings during intrathecal infusion tests. J Neurosurg. 1997;87(1):34-40.

10. Newman WD, Hollman AS, Dutton GN, Carachi R. Measurement of optic nerve sheath diameter by ultrasound: a means of detecting acute raised intracranial pressure in hydrocephalus. Br J Ophthalmol. 2002;86(10):1 109-13.

11. Blaivas M, Theodoro D, Sierzenski PR. Elevated intracranial pressure detected by bedside emergency ultrasonography of the optic nerve sheath. Acad Emerg Med. 2003;10(4):376-81.

12. Helmke K, Burdelski M, Hansen HC. Detection and monitoring of intracranial pressure dysregulation in liver failure by ultrasound. Transplantation. 2000;70(2):392-5.

13. Tayal VS, Neulander M, Norton HJ, Foster T, Saunders T, Blaivas M. Emergency department sonographic measurement of optic nerve sheath diameter to detect findings of increased intracranial pressure in adult head injury patients. Ann Emerg Med. 2007;49(4):508-14. 
14. Kimberly HH, Shah S, Marill K, Noble V. Correlation of optic nerve sheath diameter with direct measurement of intracranial pressure. Acad Emerg Med. 2008;15(2):201-4.

15. Moretti R, Pizzi B. Ultrasonography of the optic nerve in neurocritically ill patients. Acta Anaesthesiol Scand. 2011;55(6):644-52.

16. Seo H, Kim YK, Shin WJ, Hwang GS. Ultrasonographic optic nerve sheath diameter is correlated with arterial carbon dioxide concentration during reperfusion in liver transplant recipients. Transplant Proc. 2013;45(6):2272-6.

17. Rajajee V, Fletcher JJ, Rochlen LR, Jacobs TL. Comparison of accuracy of optic nerve ultrasound for the detection of intracranial hypertension in the setting of acutely fluctuating vs stable intracranial pressure: post-hoc analysis of data from a prospective, blinded single center study. Crit Care. 2012;16(3):R79.

18. Steiner LA, Andrews PJ. Monitoring the injured brain: ICP and CBF. Br J Anaesth. 2006:97(1):26-38.

19. Fahy BG, Barnas GM, Nagle SE, Flowers JL, Njoku MJ, Agarwal M. Effects of Trendelenburg and reverse Trendelenburg postures on lung and chest wall mechanics. J Clin Anesth. 1996;8(3):236-44.

20. Guerci AD, Shi AY, Levin H, Tsitlik J, Weisfeldt ML, Chandra N. Transmission of intrathoracic pressure to the intracranial space during cardiopulmonary resuscitation in dogs. Circ Res. 1985;56(1):20-30.

21. Whiteley JR, Taylor J, Henry M, Epperson TI, Hand WR. Detection of elevated intracranial pressure in robot-assisted laparoscopic radical prostatectomy using ultrasonography of optic nerve sheath diameter. J Neurosurg Anesthesiol. 2015;27(2):155-9.

22. Verdonck P, Kalmar AF, Suy K, Geeraerts T, Vercauteren M, Mottrie A, et al. Optic nerve sheath diameter remains constant during robot assisted laparoscopic radical prostatectomy. PLoS One. 2014;9(11):e111916.

23. Holmstrom A, Akeson J. Desflurane increases intracranial pressure more and sevoflurane less than isoflurane in pigs subjected to intracranial hypertension. J Neurosurg Anesthesiol. 2004;16(2):136-43.

24. Kalmar AF, Foubert L, Hendrickx JF, Mottrie A, Absalom A, Mortier EP, et al. Influence of steep Trendelenburg position and $\mathrm{CO}(2)$ pneumoperitoneum on cardiovascular, cerebrovascular, and respiratory homeostasis during robotic prostatectomy. Br J Anaesth. 2010;104(4):433-9.

25. Choi DK, Lee IG, Hwang JH. Arterial to end-tidal carbon dioxide pressure gradient increases with age in the steep Trendelenburg position with pneumoperitoneum. Korean J Anesthesiol. 2012;63(3):209-15.

26. Chin JH, Choi DK, Hwang JH, Kim YK. Re: increase in intracranial pressure during carbon dioxide pneumoperitoneum with steep Trendelenburg positioning proven by ultrasonographic measurement of optic nerve sheath diameter. J Endourol. 2015;29(1):100-1.

27. Park EY, Koo BN, Min KT, Nam SH. The effect of pneumoperitoneum in the steep Trendelenburg position on cerebral oxygenation. Acta Anaesthesiol Scand. 2009;53(7):895-9.

28. Harrison GR. The effect of posture on cerebral oxygenation during abdominal surgery. Anaesthesia. 2001;56(12):1181-4.

29. Lee JR, Lee PB, Do SH, Jeon YT, Lee JM, Hwang JY, et al. The effect of gynaecological laparoscopic surgery on cerebral oxygenation. J Int Med Res. 2006;34(5):531-6.

30. Closhen D, Treiber AH, Berres M, Sebastiani A, Werner C, Engelhard K, et al. Robotic assisted prostatic surgery in the Trendelenburg position does not impair cerebral oxygenation measured using two different monitors: A clinical observational study. Eur J Anaesthesiol. 2014;31(2):104-9.

31. Choi SH, Kim SH, Lee SJ, Soh SR, Oh YJ. Cerebral oxygenation during laparoscopic surgery: jugular bulb versus regional cerebral oxygen saturation. Yonsei Med J. 2013:54(1):225-30.

32. Romagnuolo L, Tayal V, Tomaszewski C, Saunders T, Norton HJ. Optic nerve sheath diameter does not change with patient position. Am J Emerg Med. 2005;23(5):686-8.

33. Matta BF, Heath KJ, Tipping K, Summors AC. Direct cerebral vasodilatory effects of sevoflurane and isoflurane. Anesthesiology. 1999;91(3):677-80.

34. Dubourg J, Javouhey E, Geeraerts T, Messerer M, Kassai B. Ultrasonography of optic nerve sheath diameter for detection of raised intracranial pressure: a systematic review and meta-analysis. Intensive Care Med. 2011;37(7):1059-68.

\section{Submit your next manuscript to BioMed Central and take full advantage of:}

- Convenient online submission

- Thorough peer review

- No space constraints or color figure charges

- Immediate publication on acceptance

- Inclusion in PubMed, CAS, Scopus and Google Scholar

- Research which is freely available for redistribution

Submit your manuscript at www.biomedcentral.com/submit 